"Determining the importance of high-reliability healthcare organizations during the Covid-19 pandemic: Evidence from healthcare workers in Turkey"

\begin{tabular}{|c|c|}
\hline \multirow{5}{*}{ AUTHORS } & Imran Sarihasan (iD) \\
\hline & Judit Oláh (D) \\
\hline & Main Al-Dalahmeh (D) \\
\hline & Allam Yousuf (iD) \\
\hline & Krisztina Dajnoki (D) \\
\hline ARTICLE INFO & $\begin{array}{l}\text { Imran Sarihasan, Judit Oláh, Main AI-Dalahmeh, Allam Yousuf and Krisztina } \\
\text { Dajnoki (2021). Determining the importance of high-reliability healthcare } \\
\text { organizations during the Covid-19 pandemic: Evidence from healthcare workers } \\
\text { in Turkey. Problems and Perspectives in Management, 19(3), 345-355. } \\
\text { doi:10.21511/ppm.19(3).2021.28 }\end{array}$ \\
\hline DOI & http://dx.doi.org/10.21511/ppm.19(3).2021.28 \\
\hline RELEASED ON & Friday, 17 September 2021 \\
\hline RECEIVED ON & Monday, 21 June 2021 \\
\hline \multirow[t]{2}{*}{ ACCEPTED ON } & Tuesday, 17 August 2021 \\
\hline & $(\mathrm{cc})$ EY \\
\hline LICENSE & $\begin{array}{l}\text { This work is licensed under a Creative Commons Attribution } 4.0 \text { International } \\
\text { License }\end{array}$ \\
\hline JOURNAL & "Problems and Perspectives in Management" \\
\hline ISSN PRINT & $1727-7051$ \\
\hline ISSN ONLINE & $1810-5467$ \\
\hline PUBLISHER & LLC "Consulting Publishing Company "Business Perspectives" \\
\hline FOUNDER & LLC "Consulting Publishing Company "Business Perspectives" \\
\hline
\end{tabular}

NUMBER OF REFERENCES

52
NUMBER OF FIGURES

0
NUMBER OF TABLES

4

(C) The author(s) 2021. This publication is an open access article. 


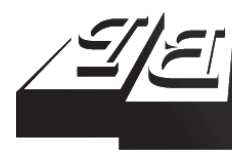

BUSINESS PERSPECTIVES

O

LLC "CPC "Business Perspectives" Hryhorii Skovoroda lane, 10, Sumy, 40022, Ukraine www.businessperspectives.org

Received on: $21^{\text {st }}$ of June, 2021 Accepted on: 17th of August, 2021 Published on: $17^{\text {th }}$ of September, 2021

() Imran Sarihasan, Judit Oláh, Main Al-Dalahmeh, Allam Yousuf, Krisztina Dajnoki, 2021

Imran Sarihasan, Doctor in Labor Economics, Károly Ihrig Doctora School of Management and Business Debrecen, University of Debrecen, Hungary.

Judit Oláh, Doctor of the Hungarian Academy of Sciences (DSc), Professor Institute of Applied Informatics and Logistics, University of Debrecen, Hungary; College of Business and Economics, University of Johannesburg South Africa. (Corresponding author)

Main Al-Dalahmeh, Ph.D., Candidate in Economics and Business, Károly Ihrig Doctoral School of Management and Business Debrecen, University of Debrecen, Hungary.

Allam Yousuf, Doctor in Business, Károly Ihrig Doctoral School of Management and Business Debrecen, University of Debrecen, Hungary.

Krisztina Dajnoki, Ph.D. in Business and Management, Associate Professor, Faculty of Economics, University of Debrecen, Hungary.

This is an Open Access article distributed under the terms of the Creative Commons Attribution 4.0 International license, which permits unrestricted re-use, distribution, and reproduction in any medium, provided the original work is properly cited.

Conflict of interest statement: Author(s) reported no conflict of interest
Imran Sarihasan (Hungary), Judit Oláh (Hungary; South Africa), Main Al-Dalahmeh (Hungary), Allam Yousuf (Hungary), Krisztina Dajnoki (Hungary)

\section{DETERMINING THE IMPORTANCE OF HIGH-RELIABILITY HEALTHCARE ORGANIZATIONS DURING THE COVID-19 PANDEMIC: EVIDENCE FROM HEALTHCARE WORKERS IN TURKEY}

\begin{abstract}
The Covid-19 pandemic has caused changes in the social and economic environments for healthcare. Particularly, to avoid spreading the Coronavirus pandemic, release the stress among healthcare workers, and make them work effectively during the epidemic, high-reliability healthcare organizations give great importance to the improvement of their functions. This study aims to show the importance of high-reliability healthcare organizations comparing their effectiveness during a pandemic by applied qualitative research method with many statistical analyses. In order to achieve the aim of the study, a Likert scale survey technique is used to collect the data by using an online survey. 280 healthcare workers filled the survey from January 17, 2021, to February 22, 2021. Based on the outcomes of the analyses, it has been found that such functions as shared knowledge pattern, provision of self-care, awareness of the coronavirus consequences at the workplace of high-reliability healthcare organizations have a positive and significant relationship at $\mathrm{p}<0.01$ level with taken appropriate measures against coronavirus variable. Self-awareness of organizational role, organizational resources to provide safety, flexibility of work, environmental safety, and collective mindfulness do not have any relationship with the appropriate measures against Covid-19 variable. This outcome indicates that shared knowledge pattern, provision of self-care, and awareness of the coronavirus consequences at the workplace have a more important role in combating Covid-19 in high-reliability healthcare organizations.
\end{abstract}

\section{Keywords management, epidemic, health literacy, occupational health, Covid-19}

JEL Classification I10, I13

\section{INTRODUCTION}

In December 2019, an outbreak of pneumonia connected with a new coronavirus (Covid-19) has been reported in most parts of the world, and its rapid and exponential distribution forced the World Health Organization (WHO) to declare it a pandemic. Since then, the world is facing one of the worst pandemics in the history of humankind. The Covid-19 has affected people in general and employees in particular as they have an additional safety hazard whirling around them. In addition, many countries are adopting measures such as social distancing, imprisonment, and quarantine to contain the distribution of the infection (Menon \& Padhy, 2020). The Covid-19 has spread rapidly across all continents, affecting social and economic resources worldwide (Sarti et al., 2020) and since the appearance of the pandemic, healthcare systems have experienced terrible consequences (Liberati et al., 2018). 
Despite the implementation of lockdown and restrictions in most parts of the world, healthcare workers are inevitable to be physically present at the workplace due to their job, which has raised a thoughtful concern for their physical and psychological health. Healthcare workers (HCWs) have manned the front line, facing the most intricate and dangerous challenges, while caring for Covid-19 patients in high-risk environments (Di Tella et al., 2020). Moreover, practically all healthcare workers in affected areas have been confronting serious challenges, beyond those they normally face in the workplace, i.e., the lack of protective equipment or unsafe working conditions, exacerbated by long shifts exposing them to both mental and physical exhaustion (Piper \& Withers, 2018).

In response, healthcare organizations have sharply changed processes for this new environment (Van Stralen \& Mercer, 2020). As a result, during the pandemic, high-reliability healthcare organizations are starting to be given much more importance to such functions as shared knowledge pattern, provision of self-care, organizational resources to provide safety, flexibility of work, environmental safety, collective mindfulness, awareness of the Covid-19 consequences at the workplace (Day et al., 2018). Additionally, to reduce exposure and alleviate the anxieties of healthcare workers with irregular hours and higher workloads (Blake et al., 2020), these functions have crucial importance.

\section{LITERATURE REVIEW, AIM AND HYPOTHESES DEVELOPMENT}

Particularly during the Covid-19 pandemic, organizational reliability has become an essential scientific concept among researchers. Although there is no universally accepted definition of the term, it has been praised for being an important aspect of daily life (Bieńkowska et al., 2020). Additionally, the meaning of high-reliability healthcare organization (HRO) has been continuously changing based on social systems and networks, as well as human activity, functions, and roles in organizations. In this regard, Lam (1998) defined organizational reliability as the relative strength of an individual's identification with the involvement in a specific organization. Considering reliability from that perspective, Mazdeh and Hesamamiri (2014) and Labrague and De Los Santos (2020) also emphasized that it is a combination of organizational support with resources provided to the organization due to the individual's strong belief and acceptance of organizational aims and a sincere desire to remain with the organization and work efficiently towards its goals. All those factors are also vital for enhancing organizational success and fulfilling key organizational elements, such as motivation, communication, interaction, goal setting, control, and performance (Katz \& Kahn, 1979). Thus, organizations search for approaches to strengthen their reliability to adapt and manage unexpected situations during a crisis.

In this regard, HROs have been given substantial attention to identifying the indicators of mishaps in organizational performance and approach elucidates and specifies reliability and effectiveness while operating in complicated and uncertain environments (Khorsandi \& Aven, 2014). Furthermore, HROs ensure that every employee in the organization not only feels free to speak up about any concerns but also recognizes the responsibility to do so because the organizational core values are dependent on information exchange among departments (Chassin \& Loeb, 2013), which is a high-priority component to achieve. Additionally, informed culture is also the result of safety and reliability in the organization - feeling free to speak up about the organization's shortfalls also enhances the concept of 'mindfulness' among employees in avoiding failures, increasing understanding in operations, confirming their commitment to resilience and deferring to experts in hazard-laden environments (Khorsandi \& Aven, 2014; Mazdeh \& Hesamamiri, 2014).

It is a well-known fact that HRO provides care, quality and safety for employees, as well as patients, and respond effectively in unexpected crises in HRO (Melnyk, 2012). Moreover, to survive crises, an organization needs to create a shared knowledge pattern upon which team coordination is facilitated, with HROs creating suitable environments for it as well (Obrenovic et al., 2020). 
However, as Chassin and Loeb (2013) emphasized, during the pandemic, high reliability also caused some problems related to HCWs. For instance, workers in a hospital unexpectedly developed a keen sense of mindfulness and began to identify all the unsafe conditions they encountered from the moment they arrived at the hospital during the pandemic. Consequently, predicaments caused by the virus become overwhelming for them. Simultaneously, as Covid-19 itself is a contagious disease, the fear of being infected in addition to the long working hours occupied in high-risk environments can also influence the mental well-being of workers in healthcare organizations (Giorgi et al., 2020). Additionally, clashing messages from specialists are among the major stressors that add to the mental weight related to Covid-19 among HCWs (McGowan et al., 2020). Thus, high reliability healthcare organizations have the ability to prevent employees' suffering as well as mitigate how the pandemic influences their performance in the organization (Walton et al., 2020).

In contrast, Covid-19 also led to a sudden change in the structure of the HROs, the consequences of which are visibly worse in many countries across the world (Obrenovic et al., 2020). Notably, enabling and creating mechanisms for social distancing and providing protective equipment such as masks, gloves, etc. for HCWs in hospitals are vital in augmenting employees' reliability and performance as well as in impeding the virus from peaking at uncontrollable levels (Davidson et al., 1978). Supporting staff in tangible ways is another main element for HROs (Caligiuri et al., 2020). Confirming this, Weick (1987) highlighted that supporting staff in an organization has led to their increased efficiency in composing unique solutions to problems in unforeseen situations. All these elements contribute to reducing the anxiety related to the Covid-19 and helping HCWs maintain their well-being, aid organizational reliability, and boost their productivity (Kiziltan \& Sarihasan, 2016; Obrenovic et al., 2020; Jiménez et al., 2021). Additionally, HRO must have effective leadership in system management, organizational knowledge pattern, and measurement to manage all changes during the pandemic.

HRO during this crisis should focus on five key elements: remaining calm, communicating, col- laborating, coordinating, and providing support to employees (Nicola et al., 2020). Besides, HROs help creating shared accountability and ensure others know goals, roles, time, and resources to receive feedback toward the organizational goal during the pandemic (Day et al., 2018). Thus, in HROs of management science, for instance, leadership, support, providing essential materials, organizational structure, and technology (Day et al., 2018) are very significant for managing Covid-19 as a team.

Thus, the aim of the study is to determine the importance of high-reliability healthcare organizations and show which functions are most critical for taking adequate anti-Covid-19 measures to protect the organization and its healthcare workers.

Based on the aim of the study and the literature review, this study has developed two main hypotheses:

H1: Work environment tends to have a more significant and positive impact on high-reliability healthcare organizations than other functions during the Covid-19 pandemic.

H2: Organizational awareness tends to have a more significant and positive impact on high-reliability healthcare organizations than other functions during the Covid-19 pandemic.

\section{METHODOLOGY}

Employee survey questions (WorkTango, 2020) were used to measure HRO's functions to apply them to HCWs during the Covid-19 outbrake in Turkey. The data of the study were collected by an online questionnaire created through Google Forms and sent to the participants on social media platforms (WhatsApp, Telegram, and Facebook groups). The first part of the questionnaire gave information on the study and it was returned automatically upon completion by each participant. Although 280 HCWs participated in the survey, the final valid number due to some missing data was 275 . The survey collected data on the skills of qualified respondents since the pandemic began. 
The survey elements contained Likert-scale type choices and short-response items to discover the demographics, work circumstances, recent service provision, leadership role, environmental safety, and psychological well-being of HCWs in Turkey. All completed questionnaires were received between January 17, 2021, and February 22, 2021.

Underpinned by the positivist philosophical paradigm, this study was based on a qualitative research approach. Several statistical analyses were applied by using the SPSS 23. First, descriptive statistics were employed to specify the characteristics of variables. The data are presented as a number, mean and standard deviation (SD), maximum and minimum numbers (Uyanık \& Güler, 2013). OLS regression analyses have been employed to indicate the relationship between two or more variables and make predictions about the topic using this link and test the hypotheses of the study (Tanaka et al., 1989). Lastly, explanatory factor analyses were applied to identify latent variables under the other variables.

As indicated above, the main aim of the HRO is to take appropriate actions in response to unexpected circumstances, such as the Covid-19 pandemic. Other factors applied by the organization affect it. Thus, this study has one dependent variable, which is "taken appropriate measures during Covid-19" and eight independent variables as shared knowledge pattern, provision of self-care, self-awareness of organizational role, organizational resources to provide safety, flexibility to deal with change, environmental safety, collective mindfulness and awareness of the Covid-19 consequences at the workplace as shown in Table 1.

The hypotheses were tested by using the ordinary linear regression (OLS) models (Equation 1) with heteroscedasticity consistent and robust (HAC) standard errors.

$$
\begin{aligned}
& \text { TAMAc_ } 19_{i}=\beta_{0}+\beta_{1} S K P_{i}+ \\
& +\beta_{2} P C_{i}+\beta_{3} S_{W O R_{i}}+\beta_{4} \text { ORS }_{i}+ \\
& +\beta_{5} \mathrm{FOW}_{i}+\beta_{6} \text { ESc_19 }{ }_{i}+ \\
& +\beta_{7} C m c \_19_{i}+\beta_{8} C A c \_19_{i}+\varepsilon_{i} \text {, }
\end{aligned}
$$

where TAMAc 19 - taken appropriate measures against Covid-19, SKP - shared knowledge pattern, $P S C$ - provision of self-care, $S W O R$ - self-awareness of organizational role, ORS - organizational resources to provide safety, FOW - flexibility of work, ESc 19 - environmental safety during Covid-19, Cmc 19 - collective mindfulness during Covid-19, $C \bar{A} c \quad 19$ - awareness of the Covid-19 consequences at the workplace.

\section{RESULTS}

The data analysis began with descriptive statistics such as mean, SD, the minimum and the maximum number of variables as shown in Table 2.

\begin{tabular}{|c|c|c|}
\hline Dependent variable & Abbreviation & Definition \\
\hline $\begin{array}{l}\text { V1 Taken appropriate measures against } \\
\text { Covid-19 }\end{array}$ & TAMAc_19 & $\begin{array}{l}\text { HRO has taken appropriate measures against Covid-19 to protect } \\
\text { organizations and healthcare workers }\end{array}$ \\
\hline V2 Shared knowledge pattern & SKP & $\begin{array}{l}\text { Senior leaders in HRO have done a good job of sharing information } \\
\text { regarding Covid-19 }\end{array}$ \\
\hline V3 Provision of self-care & PSC & HRO care about HCWs in the organization \\
\hline V4 Self-awareness of organizational role & SWOR & $\mathrm{HCW}$ is aware of its role in the $\mathrm{HRO}$ \\
\hline $\begin{array}{l}\text { V5 Organizational resources to provide } \\
\text { safety }\end{array}$ & ORS & $\begin{array}{l}\text { HRO has sufficient resources to provide a safe environment for HCW } \\
\text { during the pandemic }\end{array}$ \\
\hline V6 Flexibility of work & FOW & $\begin{array}{l}\text { When HCWs think something is unsafe, leadership will not cause } \\
\text { them trouble and they can stop working }\end{array}$ \\
\hline V7 Environmental safety during Covid-19 & ESC_19 & $\begin{array}{l}\text { Work environment without fear of being infected and there is a } \\
\text { social-distancing system established during the pandemic in the HRO }\end{array}$ \\
\hline V8 Collective mindfulness during Covid-19 & CMc_19 & All HCWs in the HRO take Covid-19 and its consequences seriously \\
\hline $\begin{array}{l}\text { V9 Awareness of the Covid-19 } \\
\text { consequences at the workplace }\end{array}$ & CAc_19 & Healthcare workers take Covid-19 consequences seriously \\
\hline
\end{tabular}

According to the function taken appropriate measures against Covid-19 ( $\mathrm{M}=1.11, \mathrm{SD}=0.31)$,

Table 1. Description, abbreviation, and definitions of main variables 
Table 2. Descriptive statistic of variables

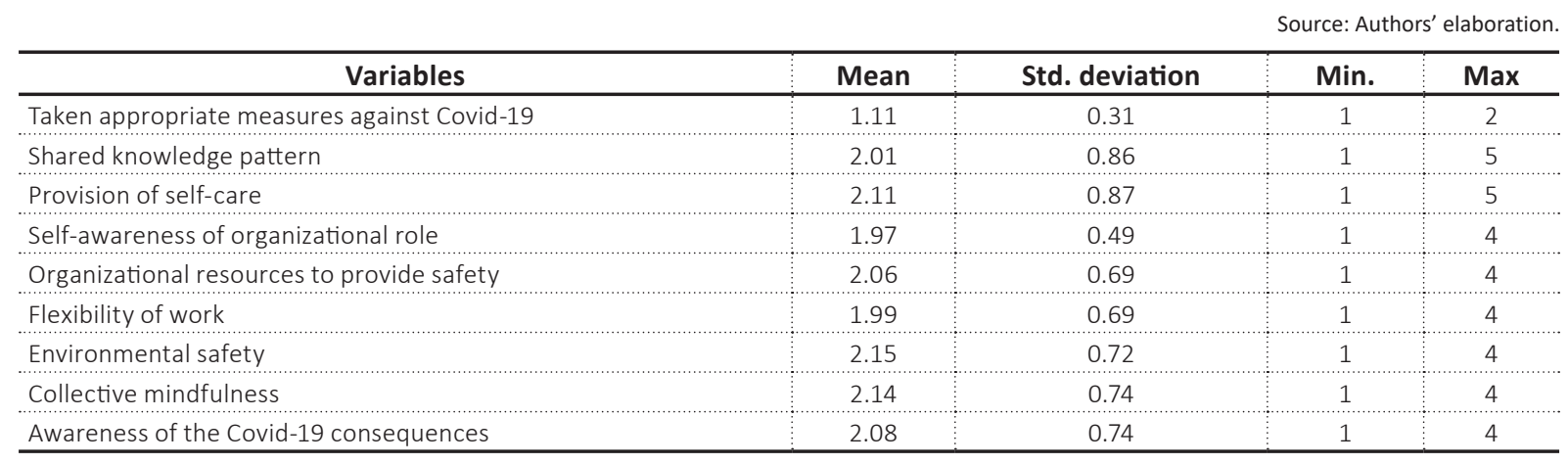

the outcome shows that there is an agreement among respondents that HROs take appropriate measures against Covid-19. M equals $1.11=2$ matches with the "yes" on the used scale. Standard deviation refers to the extent to which the values are far or close to the mean. The shared knowledge pattern value is between $2.01 \pm 0.86=\{2.330\}$. This result indicates that respondents are agree based on the used scale that shared knowledge pattern is applied during the Covid-19 at HRO. In the case of the provision of self-care, $1.97 \pm 0.49=\{4.020\}$ demonstrates the majority of the respondents disagree that self-care is not perfectly applied in $\mathrm{HRO}$ based on the used scale. On the other hand, organizational resources to provide safety show the value $2.06 \pm 0.69=\{2.985\}$; thus, the majority of the respondents agree on HRO provide resources necessary for safety during Covid-19. For the other functions, the majority of the respondents stated that for the flexibility of work the value is $1.99 \pm 0.69=\{2.884\}$ (agree), for environmental safety $-2.15 \pm 0.72=\{1.043\}$ (strongly agree), for collective mindfulness $-2.14 \pm 0.74=\{2.891\}$ (agree), for awareness of the Covid-19 consequences $-2.08 \pm 0.74=\{2.810\}$ (agree).

The second step is to check the reliability of the used measures and the extent to which it is consistent, by using Cronbach's alpha to measure the reliability of the variables used in the questionnaire and the degree of homogeneity in the measurement.

Loading values to be accepted are lower $>0.60$. Of the 8 items in Table 2, the minimum value was higher than 50\% (Meng, 2020). The results show the statistical significance of the relationships between the items and constructs and the reliability of individual items. The results of Cronbach's alpha test for each variable are summarized in Table 3.

It can be noted from the value of the Cronbach's alpha of the current study equalize 0.789 , which means the scale or the questionnaire used to measure the variables is a reliable and steady one. If alpha's value is bound between 0 and 1 , it can be used

Table 3. Reliability test

Source: Authors' elaboration.

\begin{tabular}{|c|c|c|c|}
\hline No. & Scale & Cronbach's alpha & Loadings \\
\hline & For IV and DV (9 items) & 0.789 & \\
\hline \multicolumn{4}{|c|}{ Functions of work environment } \\
\hline V5 & Organizational resources to provide safety & & .588 \\
\hline V7 & Environmental safety during Covid-19 & & .639 \\
\hline V8 & Collective mindfulness during Covid-19 & & .807 \\
\hline V9 & Awareness of the Covid-19 consequences at the workplace & & .807 \\
\hline \multicolumn{4}{|c|}{ Functions of organizational awareness } \\
\hline V2 & Shared knowledge pattern & & .707 \\
\hline V3 & Senior leaders care about my health and safety & & .603 \\
\hline V4 & Self-awareness of organizational role & & .733 \\
\hline \multirow[t]{3}{*}{ V6 } & Flexibility of work & & .560 \\
\hline & DV & & \\
\hline & High-reliability healthcare organization has taken appropriate measures against Covid-19 & & \\
\hline
\end{tabular}


with questionnaires, which have a scale from 0 as the worst value, to 5 as the best, and if the alpha value is 0.70 , this can be acceptable; indeed, lower values have also been accepted (Tavakol \& Dennick, 2011).

Factor analysis was done to find groups of variables that are highly intercorrelated. Based on the outcome, two groups of IV are established, and it can be indicated from here that loadings values ranged between [.560-.807]. Factor loadings are scaled from 0 to 1 and are essentially coefficients that show how strong the relationship is between the variable and the factor.

Table 4. OLS regression for Equation (1)

\begin{tabular}{|c|c|c|}
\hline \multicolumn{3}{|c|}{ DV: TAMAc-19 } \\
\hline IVs: & Model 1 & Model 2 \\
\hline \multirow{2}{*}{ Constant } & $0.57 * * *$ & $0.48^{* * *}$ \\
\hline & 8.751 & 9.939 \\
\hline \multirow{2}{*}{ SKP } & $0.64^{* * *}$ & $.026^{* * *}$ \\
\hline & 3.689 & 16.289 \\
\hline \multirow{2}{*}{ PSC } & $0.06 * * *$ & $0.49 * * *$ \\
\hline & 3.637 & 3.038 \\
\hline \multirow{2}{*}{ SWOR } & -0.04 & \\
\hline & $(-1.666)$ & \\
\hline \multirow{2}{*}{ ORS } & -0.08 & \\
\hline & $(-0.385)$ & \\
\hline \multirow{2}{*}{ FOW } & -0.03 & \\
\hline & $(-1.459)$ & \\
\hline \multirow{2}{*}{ Esc-19 } & -0.01 & \\
\hline & $(-0.893)$ & \\
\hline \multirow{2}{*}{ Cmc-19 } & -0.22 & \\
\hline & $(-1.077)$ & \\
\hline \multirow{2}{*}{ Cac-19 } & $.046^{* * *}$ & $.037^{* * *}$ \\
\hline & 2.753 & 2.275 \\
\hline Observations & \multicolumn{2}{|c|}{275} \\
\hline $\operatorname{Adj} . R^{2}$ & 0.64 & 0.63 \\
\hline F-Test & $62.011 * * *$ & 44. $320 * * *$ \\
\hline VIF (Max) & 1.694 & 1.483 \\
\hline
\end{tabular}

Notes: Heteroscedasticity robust $(\mathrm{HC}) \mathrm{t}$-statistics of the standard errors are in parentheses; DV: dependent variable; IVs: independent variables; ${ }^{* * *}$ - significance at $1 \%, * *-$ significance at $5 \%,{ }^{*}-$ significance at $10 \%$; the 'Variance Inflating Factor' (VIF) test is applied to check multicollinearity.

Table 4 presents the results of the estimations for heteroscedasticity consistent (HC) and ordinary least squares (OLS). The model is created based on Equation (1). Model 1 represents the full model while model 2 contains only variables that were significant in model 1 . Other insignificant variables were omitted. The F-test statistics propose that the linear regression measurement should be preferred in all models since it is significant at $p$ $<0.01$ level. The 'Variance Inflating Factor' (VIF) test is employed to check the multicollinearity. The maximum values of VIF ranges of the models are taken into consideration and all ranges are smaller than < 3.0 (Hair, 2011). Thus, this study does not have a multicollinearity issue. Model 1 is based on Equation (1); the constant of the model is significant at $p<0.01$ level. Additionally, shared knowledge pattern (SKP), provision of self-care (PSC), and awareness of the Covid-19 consequences at the workplace (CAc-19) have a positive and significant relationship at $p<0.01$ level.

Based on the result of the model, $\mathrm{H} 1$ is partially accepted: organizational resources to provide safety, flexibility of work, environmental safety during Covid-19, collective mindfulness during Covid-19 tend to have a more significant and positive impact on high-reliability healthcare organizations than other functions during the Covid-19 pandemic. $\mathrm{H} 2$ is also partially accepted: shared knowledge pattern, provision of self-care, self-awareness of organizational role, awareness of the Covid-19 consequences at the workplace tends to have a more significant and positive impact on high-reliability healthcare organizations than other functions during the Covid-19 pandemic.

\section{DISCUSSION}

To provide timely and appropriate supporting databases to sustain the health systems in addressing health issues and anticipating emerging healthcare challenges, the use of multiple elements in an iterative process in redesigning the questionnaire proves extremely useful to update and revise contents to suit health systems needs, particularly during the unexpected situation (Woei et al., 2021). Mainly, eight key behavioral dimensions of HROs are examined in this study - shared knowledge pattern, provision of self-care, self-awareness of organizational role, organizational resources to provide safety, flexibility of work, environmental safety, collective mindfulness during Covid-19, and awareness of the Covid-19 consequences.

HROs recognizing the work environments and protection required, which are favorable to 
great leadership, is crucial for sustaining leaders' work-related health (Wikström \& Dellve, 2009). Leadership is one of the chief components of HROs. It also creates an effective system equipped with processes to handle unpredictable situations for employees (Miller et al., 2009). In this study, four questions were asked to indicate the role of the senior leadership in healthcare organizations during the Covid-19. The result of the first question revealed that HCWs in the country mostly agree on the fact that senior leaders have distributed information related to the Covid-19. Particularly, during this critical time, leaders must share information and the available resources, goals, and all the feedback with HCWs - motivating them to work in effective ways and enhancing their trust in the organization (Day et al., 2018). On the other hand, healthcare organizations have a responsibility to address environmental risks to protect their workers - it is the duty of the leaders to create safe environments to safeguard their workers from the virus (Oláh et al., 2019; Olson et al., 2020). Based on the outcome of the questionnaire, most of the participants agreed that senior leaders pay attention to health and safety in healthcare organizations in Turkey. Keeping with this point of view, Vagni et al. (2020) highlighted that a secure and effective employment environment encourages a personal sense of flexibility for healthcare employees during a global health disaster such as the Covid-19 pandemic.

When dealing with a new pandemic, it is important to remember that information must be exchanged regularly between employees and senior leaders (Porat et al., 2020). It was found that 229 participants of the survey agreed that they felt comfortable communicating their concerns and conveying their suggestions about Covid-19 to the organization's leaders. Additionally, 207 participants agree that they can stop working if there is a danger of exposure or peril and the seniors will grant them respite. This awareness aids better psychosocial strength to handle circumstances in such high-risk environments. Furthermore, knowledge sharing pattern is an important component of HROs' functions, as well as in the role of leadership during the Covid-19. This outcome is supported by Frangeskou et al. (2020); namely, Covid-19 re- quires strong leadership to respond to the epidemic with strong problem-solving communication, encouraged by shared goals, shared knowledge pattern, and mutual respect among employees. Such communication may also increase the loyalty level of HCWs and empower them to speak about their apprehensions, which is one of the main aims of HROs.

On the other hand, it is essential that HRO leaders create a work environment characterized by empowerment, trust, and psychological safety to allow employees to communicate safety concerns with their administrators during the pandemic to handle the situation efficiently (Rangachari \& Woods, 2020). Supporting this point of view, Shanafelt et al. (2020) stated that leaders, particularly hospital executives, department chairs, and division chiefs may need to create progressive ways to connect with their teams and manage the pandemic in healthcare organizations. These assumptions support the importance of shared knowledge pattern as an outcome.

Additionally, it has been discovered that providing self-care is another important component that HRO should consider during the pandemic. It leads to mutual trust and essential teamwork is required to provide support and assert concerns without fear of dismissal (Baker et al., 2006). It also leads to employees confirming their trust in their organization and is particularly vital to increasing reliability between healthcare organizations and HCWs (Oláh et al., 2017; Máté et al., 2017; Alshaabani et al., 2020). This result is supported by Wallace et al. (2020), who demonstrate that providing self-care to HCWs is positively associated with a health care professional's ability to cope with death in their professional setting.

It has also been discovered that collective mindfulness is another critical component during the pandemic. Mindfulness helps to reduce to stress and anxiety, increase resilience, divergent and improve leadership flexibility. It is already a well-known fact that in HROs even minor mistakes can cause irreversible results. Thus, every HCW has to be conscious of the role and take preventative actions while working, which is 
called collective mindfulness (Miller et al., 2009; Singh et al., 2012; Tomlin et al., 2020; Di Tella et al., 2020). Furthermore, Brumback et al. (2009) provided the most compelling depiction of how high-reliability organizations maintain their safety. An environment of "collective mindfulness" in which all workers desirer was defined, and small problems or unsafe conditions were reported before they pose a substantial risk to the organization and when they are easy to answer, which is really significant during the pandemic. Lastly, this study supports that flexibility of work and environmental safety during the pandemic are two other elements, which leaders in HROs should pay more attention to than other functions.

\section{CONCLUSION}

The study aims to determine the importance of HROs' functions and also indicate which functions are more important to apply during the pandemic. To achieve the aim of the study online survey method was employed and two main hypotheses were developed. For the empirical testing, the main model used one dependent and eight independent variables.

Based on the empirical testing of the study, it has been found that shared knowledge pattern, provision of self-care, and awareness of the Covid-19 consequences have a positive and significant relationship with taken appropriated measures against Covid-19.

A key contribution emerging from this study is that sharing information with the HCW in the healthcare organization plays a crucial role to improve the productivity of work during unexpected crises. Along with that, HCW should be aware of the consequences of the pandemic. Thus, this awareness can help to reduce to spread of the virus increasing the collective mindfulness among workers. In addition, this enhancement in perceived risk improves psychological well-being among healthcare workers.

With a view of future research, this study also strongly contributes to the current literature and mainly strengthens the empirical data previously obtained in the second wave of the Covid-19. In addition, findings could have a beneficial impact on these professionals in the face of the third wave of the Covid-19 crisis.

\section{AUTHOR CONTRIBUTIONS}

Conceptualization: Imran Sarihasan.

Data curation: Imran Sarihasan, Main Al-Dalahmeh, Allam Yousuf.

Formal analysis: Imran Sarihasan, Main Al-Dalahmeh.

Funding acquisition: Krisztina Dajnoki.

Investigation: Imran Sarihasan.

Methodology: Imran Sarihasan, Main Al-Dalahmeh.

Project administration: Imran Sarihasan.

Resources: Imran Sarihasan, Main Al-Dalahmeh.

Software: Imran Sarihasan, Main Al-Dalahmeh.

Supervision: Imran Sarihasan.

Validation: Imran Sarihasan.

Visualization: Imran Sarihasan, Main Al-Dalahmeh.

Writing - original draft: Imran Sarihasan, Judit Oláh, Main Al-Dalahmeh, Allam Yousuf, Krisztina Dajnoki.

Writing - review \& editing: Imran Sarihasan, Judit Oláh, Main Al-Dalahmeh, Allam Yousuf, Krisztina Dajnoki. 


\section{ACKNOWLEDGMENTS}

We would like to thank all the healthcare workers, who filled the survey of the study. This paper is supported by EFOP-3.6.3-VEKOP-16-2017-00007- "Young researchers for talent"- supporting careers in research activities in higher education program.

\section{REFERENCES}

1. Alshaabani, A., Oláh, J., Popp, J., \& Zaien, S. (2020). Impact of distributive justice on the trust climate among Middle Eastern employees. Polish Journal of Management Studies, 21(1), 3447. http://dx.doi.org/10.17512/ pjms.2020.21.1.03

2. Baker, D. P., Day, R., \& Salas, E. (2006). Teamwork as an essential component of high-reliability organizations. Health services research, 41(4p2), 1576-1598. http://dx.doi.org/10.1111/j.14756773.2006.00566.x

3. Bieńkowska, A., Tworek, K., \& Zabłocka-Kluczka, A. (2020). Organizational Reliability: Human Resources, Information Technology and Management. Routledge.

4. Blake, H., Bermingham, F., Johnson, G., \& Tabner, A. (2020). Mitigating the psychological impact of COVID-19 on healthcare workers: a digital learning package. International journal of environmental research and public health, 17(9), 2997. https://doi.org/10.3390/ ijerph17092997

5. Brumback, G. B., Buenger, V., Fleenor, J. W., Pfeffer, J., Ree, M. J., Spector, P., \& Thayer, P. W. (2009). Managing the Unexpected: Resilient Performance in an Age of Uncertainty. Personnel Psychology, 62(3), 646-652.

6. Caligiuri. P., De Cieri, H., Minbaeva, D., Verbeke, A., \& Zimmermann, A. (2020). International HRM insights for navigating the COVID-19 pandemic: Implications for future research and practice. International Journal of Business Studies, 51(5), 697-713. Retrieved from https:// ideas.repec.org/a/pal/jintbs/ v51y2020i5d10.1057_s41267-02000335-9.html
7. Chassin, M. R., \& Loeb, J. M. (2013). High-reliability health care: Getting there from here. Milbank Quarterly, 91(3), 459-490. https://doi.org/10.1111/14680009.12023

8. Davidson, J. E. H., Hendry, D. F., Srba, F., \& Yeo. S. (1978). Econometric Modelling of the Aggregate Time-Series Relationship between Consumers' Expenditure and Income in the United Kingdom. Economic Journal, 88(352), 661-692. https:// doi.org/10.2307/2231972

9. Day, R. M., Demski, R. J., Pronovost, P. J., Sutcliffe, K. M., Kasda, E. M., Maragakis, L. L., Paine, L., Sawyer, M. D., \& Winner, L. (2018). Operating management system for high reliability: Leadership, accountability, learning and innovation in healthcare. Journal of Patient Safety and Risk Management, 23(4), 155-166. https://doi. org/10.1177/2516043518790720

10. Di Tella, M., Romeo, A., Benfante, A., \& Castelli, L. (2020). Mental health of healthcare workers during the COVID-19 pandemic in Italy. Journal of Evaluation in Clinical Practice, 26(6), 1583-1587. https://doi.org/10.1111/jep.13444

11. Frangeskou, M., Lewis, M. A., \& Vasilakis, C. (2020). Implementing standardised flow: navigating operational and professional dependencies. International Journal of Operations \& Production Management, 40(7/8), 1177-1199. https://doi. org/10.1108/IJOPM-06-2019-0493

12. Giorgi, G., Lecca, L. I., Alessio, F., Finstad, G. L., Bondanini, G., Lulli, L. G., Arcangeli, G., \& Mucci, N. (2020). COVID-19-related mental health effects in the workplace: a narrative review. International
Journal of Environmental Research and Public Health, 17(21), 7857. https://doi.org/10.3390/ ijerph17217857

13. Hair, J. F. (2011). Multivariate Data Analysis: An Overview. In M. Lovric (Ed.), International Encyclopedia of Statistical Science. Springer, Berlin, Heidelberg. http://dx.doi.org/10.1007/978-3642-04898-2_395

14. Jiménez, J. E., Manuel BlancoDonoso, L., Demerouti, E., Belda Hofheinz, S., Chico-Fernández, M., Moreno-Jiménez, B., \& Garrosa, E. (2021). The Role of Healthcare Professionals' Passion in Predicting Secondary Traumatic Stress and Posttraumatic Growth in the Face of COVID-19: A Longitudinal Approach. International Journal of Environmental Research and Public Health, 18(9), 4453. https://doi. org/10.3390/ijerph18094453

15. Katz, D. \& Kahn, R. L. (1979). The Social Psychology of Organizations ( $2^{\text {nd }}$ ed.). New York: Wiley.

16. Khorsandi, J., \& Aven, T. (2014). A risk perspective supporting organizational efforts for achieving high reliability. Journal of Risk Research, 17(7), 871-884. https://doi.org/10.1080/13669877. 2013.822912

17. Kiziltan, A., \& Sarihasan, İ. (2016). Finansal Krizlerin Kobiler Üzerindeki Etkisi Rize İli Ayakkabi Sektoru Üzerine Bir Arastirma. Recep Tayyip Erdoğan Üniversitesi Sosyal Bilimler Dergisi, 2(3), 22-42. (In Turkish).

18. Klein, K. J., Ziegert, J. C., Knight, A. P., \& Xiao, Y. (2006). Dynamic Delegation: Shared, Hierarchical, and Deindividualized Leadership in Extreme Action Teams. Administrative Science Quarterly, 
51(4), 590-621. https://doi. org/10.2189\%2Fasqu.51.4.590

19. Labrague, L. J., \& De los Santos, J. A. A. (2020). COVID-19 anxiety among front-line nurses: Predictive role of organisational support, personal resilience and social support. Journal of Nursing Management, 28(7), 1653 1661. https://doi.org/10.1111/ jonm.13121

20. Lam, S. S. K. (1998). Test-retest reliability of the organizational commitment questionnaire. Journal of Social Psychology, 138(6), 787-788. https://doi. org/10.1080/00224549809603264

21. Liberati, E. G., Peerally, M. F., \& Dixon-Woods, M. (2018). Learning from high risk industries may not be straightforward: a qualitative study of the hierarchy of risk controls approach in healthcare. International Journal for Quality in Health Care, 30(1), 39-43. http://dx.doi.org/10.1093/ intqhc/mzx163

22. Máté, D., Sarıhasan, İ., \& Dajnoki, K. (2017). The relations between labour market institutions and employment of migrants. Amfiteatru Economic Journal, 19(46), 806-820. Retrieved from http://hdl.handle. net/10419/169106

23. Mazdeh, M. M., \& Hesamamiri, R. (2014). Knowledge management reliability and its impact on organizational performance: An empirical study. Program, 48(2), 102-126. https://doi.org/10.1108/ PROG-01-2013-0001

24. McGowan, M. L., Norris, A. H., \& Bessett, D. (2020). Care Churn - Why Keeping Clinic Doors Open Isn't Enough to Ensure Access to Abortion. New England Journal of Medicine, 383(6), 508510. http://dx.doi.org/10.1056/ NEJMp2013466

25. Melnyk, B. M. (2012). Achieving a high-reliability organization through implementation of the ARCC model for systemwide sustainability of evidencebased practice. Nursing Administration Quarterly, 36(2), 127-135. https://doi.org/10.1097/ naq.0b013e318249fb6a
26. Meng, M., Lei, J., Jiao, J., \& Tao, Q. (2020). How does strategic flexibility affect bricolage: The moderating role of environmental turbulence. Plos one, 15(8), 0238030. https:// dx.doi.org/10.1371\%2Fjournal. pone. 0238030

27. Menon, V., \& Padhy, S. K. (2020) Ethical dilemmas faced by health care workers during COVID-19 pandemic: Issues, implications and suggestions. Asian Journal of Psychiatry, 51, 102116. https://dx.doi.org/10.1016\%2Fj. ajp.2020.102116

28. Miller, K., Riley, W., \& Davis, S. (2009). Identifying key nursing and team behaviours to achieve high reliability. Journal of Nursing Management, 17(2), 247-255. https://doi.org/10.1111/j.13652834.2009.00978.x

29. Nicola, M., Sohrabi, C., Mathew, G., Kerwan, A., Al-Jabir, A., Griffin, M., Agha, M., \& Agha, R. (2020). Health policy and leadership models during the COVID-19 pandemic: A review. International Journal of Surgery, 81, 122-129. https://dx.doi.org/10.1016\%2Fj. ijsu.2020.07.026

30. Obrenovic, B., Du, J., Godinic, D., Tsoy, D., Khan, M. A. S., \& Jakhongirov, I. (2020). Sustaining enterprise operations and productivity during the COVID-19 pandemic: Enterprise effectiveness and sustainability model. Sustainability, 12(15), 5981. https://doi.org/10.3390/ su12155981

31. Oláh, J., Karmazin, G., Farkasné Fekete, M., \& Popp, J. (2017). An examination of trust as a strategical factor of success in logistical firms. Business: Theory and Practice, 18(1), 171177. https://doi.org/10.3846/ btp. 2017.018

32. Oláh, J., Kovács, S., Virglerova, Z., Lakner, Z., Kovacova, M., \& Popp, J. (2019). Analysis and Comparison of Economic and Financial Risk Sources in SMEs of the Visegrad Group and Serbia. Sustainability, 11(7), 1853. https:// doi.org/10.3390/su11071853

33. Olson, K., Shanafelt, T., \& Southwick, S. (2020). Pandemic-
Driven Posttraumatic Growth for Organizations and Individuals. JAMA - Journal of the American Medical Association, 324(18), 18291830. https://doi.org/10.1001/ jama.2020.20275

34. Piper, N., \& Withers, M. (2018). Forced transnationalism and temporary labour migration: implications for understanding migrant rights. Identities, 25(5), 558-575. https://doi.org/10.1080/1 070289X.2018.1507957

35. Porat, T., Nyrup, R., Calvo, R. A., Paudyal, P., \& Ford, E. (2020). Public Health and Risk Communication During COVID-19 - Enhancing Psychological Needs to Promote Sustainable Behavior Change. Frontiers in Public Health, 8(27), 637. https://doi.org/10.3389/ fpubh.2020.573397

36. Rangachari, P., \& Woods, J. L. (2020). Preserving Organizational Resilience, Patient Safety, and Staff Retention during COVID-19 Requires a Holistic Consideration of the Psychological Safety of Healthcare Workers. International Journal of Environmental Research and Public Health, 17(12), 4267. https://dx.doi. org/10.3390\%2Fijerph17124267

37. Riley, W. (2009). High reliability and implications for nursing leaders. Journal of Nursing Management, 17(2), 238-246. https://doi.org/10.1111/j.13652834.2009.00971.x

38. Sarti, T. D., Lazarini, W. S., Fontenelle, L. F., \& Almeida, A. P. S. C. (2020). Qual o papel da Atenção Primária à Saúde diante da pandemia provocada pela COVID-19? Epidemiologia e Serviços de Saúde, 29(0), 2020166. (In Portuguese).

39. Shanafelt, T., Ripp, J., \& Trockel, M. (2020). Understanding and Addressing Sources of Anxiety among Health Care Professionals during the COVID-19 Pandemic. JAMA - Journal of the American Medical Association, 323(21), 2133-2134. https://doi. org/10.1001/jama.2020.5893

40. Singh, H., Giardina, T. D., Petersen, L. A., Smith, M. W., Paul, 
L. W., Dismukes, K., \& Thomas, E.J. (2012). Exploring situational awareness in diagnostic errors in primary care. BMJ Quality and Safety, 21(1), 30-38. https://doi. org/10.1136/bmjqs-2011-000310

41. Tanaka, H., Hayashi, I., \& Watada, J. (1989). Theory and Methodology Possibilistic linear regression analysis for fuzzy data. European Journal of Operational Research, European Journal of Operational Research, 40(3), 389396.

42. Tavakol, M., \& Dennick, R. (2011). Making sense of Cronbach's alpha. International Journal of Medical Education, 2, 53-55. https://dx.doi. org/10.5116\%2Fijme.4dfb.8dfd

43. Tomlin, J., Dalgleish-Warburton, B., \& Lamph, G. (2020). Psychosocial Support for Healthcare Workers During the COVID-19 Pandemic. Frontiers in Psychology, 11(2), 155. https://dx.doi. org/10.3389\%2Ffpsyg.2020.01960

44. Uyanık, G. K., \& Güler, N. (2013). A Study on Multiple Linear Regression Analysis. Procedia Social and Behavioral Sciences, 106, 234-240. http://dx.doi. org/10.1016/j.sbspro.2013.12.027
45. Vagni, M., Maiorano, T., Giostra, V., \& Pajardi, D. (2020). Hardiness, Stress and Secondary Trauma in Italian Healthcare and Emergency Workers during the COVID-19 Pandemic. Sustainability, 12(14), 5592. https://doi.org/10.3390/ su12145592

46. Van Stralen, D., \& Mercer, T. (2020). Pandemic COVID-19, the High-Reliability Organization (HRO), and the Ecology of Fear. Neonatology Today, 15(12), 129-138. http://dx.doi. org/10.51362/neonatology.today/2020121512129138

47. Wallace, C. L., Wladkowski, S. P., Gibson, A., \& White, P. (2020). Grief During the COVID-19 Pandemic: Considerations for Palliative Care Providers. Journal of pain and symptom management, 60(1), e70-e73. https://doi.org/10.1016/j.jpainsymman.2020.04.012

48. Walton, M., Murray, E., \& Christian, M. D. (2020). Mental health care for medical staff and affiliated healthcare workers during the COVID-19 pandemic. European Heart Journal: Acute Cardiovascular Care, 9(3), 241-247. https://doi. org/10.1177/2048872620922795
49. Weick, K. E. (1987).

Organizational Culture as a Source of High Reliability. California Management Review, 29(2), 112-127. https://doi. org/10.2307\%2F41165243

50. Wikström, E., \& Dellve, L. (2009). Contemporary leadership in healthcare organizations: Fragmented or concurrent leadership. Journal of Health, Organisation and Management, 23(4), 411-428. https://doi. org/10.1108/14777260910979308

51. WorkTango. (2020). Employee Survey Templates|Covid19|Remote Work|Return to Work. Retrieved March 31, 2021, from https://worktango.com/covid19-remote-work-free-surveytemplates-offer/

52. Woei, D., Chong, Q., Jawahir, S., Tan, H., Sararaks, S., \& Movsisyan, A. (2021). Redesigning a Healthcare Demand Questionnaire for National Population Survey: Experience of a Developing Country. International Journal of Environmental Research and Public Health Article. https://doi. org/10.3390/ijerph18094435 